\title{
Erratum to: Colour in context. Pigments and other coloured residues from the Early-Middle Holocene site of Takarkori (SW Libya)
}

\author{
Savino di Lernia ${ }^{1,2} \cdot$ Silvia Bruni $^{3} \cdot$ Irina Cislaghi $^{3} \cdot$ Mauro Cremaschi $^{4}$. \\ Marina Gallinaro $^{5,6}$ - Vittoria Guglielmi ${ }^{3}$. Anna Maria Mercuri ${ }^{7}$. Giansimone Poggi ${ }^{5}$. \\ Andrea Zerboni ${ }^{4}$
}

Published online: 28 February 2017

(C) Springer-Verlag Berlin Heidelberg 2017

\section{Erratum to: Archaeological and Anthropological Sciences DOI 10.1007/s12520-015-0229-4}

The original version of this article, unfortunately, contained error.

In the list authors, the name should be changed to "Vittoria Guglielmi" instead of the "Vittoria Gugliemi". Given in this article are the correct name of authors.

The online version of the original article can be found at http://dx.doi. org/10.1007/s12520-015-0229-4.

Savino di Lernia

savino.dilernia@uniroma1.it

Silvia Bruni

silvia.bruni@unimi.it

Mauro Cremaschi

mauro.cremaschi@unimi.it

Marina Gallinaro

marina.gallinaro@uniss.it

Anna Maria Mercuri

annamaria.mercuri@unimore.it

Andrea Zerboni

andrea.zerboni@unimi.it

1 Dipartimento di Scienze dell'Antichità, Sapienza Università di Roma, Via dei Volsci 122, 00185 Rome, Italy
2 School of Geography, Archaeology and Environmental Studies, University of the Witwatersrand, Private Bag 3, Johannesburg 2050, South Africa

3 Dipartimento di Chimica, Università degli Studi di Milano, via C. Golgi 19, 20133 Milan, Italy

4 Dipartimento di Scienze della Terra 'Ardito Desio', Università degli Studi di Milano, via L. Mangiagalli 34, 20133 Milan, Italy

5 The Archaeological Mission in the Sahara, Sapienza Università di Roma, Rome, Italy

6 Dipartimento di Storia, Scienze dell'Uomo e della Formazione, Università di Sassari, Sassari, Italy

7 Laboratorio di Palinologia e Paleobotanica, Dipartimento di Scienze della Vita, Università di Modena e Reggio Emilia, Viale Caduti in Guerra, 127, 41121 Modena, Italy 